\title{
Cryothecomonas aestivalis sp. nov., a colourless nanoflagellate feeding on the marine centric diatom Guinardia delicatula (Cleve) Hasle
}

\author{
G. Drebes ${ }^{1}$, S. F. Kühn ${ }^{2}$, A. Gmelch ${ }^{3} \&$ E. Schnepf ${ }^{3}$ \\ ${ }^{1}$ Biologische Anstalt Helgoland, Wattenmeerstation Sylt; D-25992 List/Sylt, Germany \\ ${ }^{2}$ Alfred Wegener Institut für Polar- und Meeresforschung; P. O. Box 120161, \\ D-27515 Bremerhaven, Germany \\ ${ }^{3}$ Zellenlehre, Fakultät für Biologie, Universität Heidelberg; Im Neuenheimer Feld 230, \\ D-69120 Heidelberg, Germany
}

\begin{abstract}
The vegetative life cycle, host specificity, morphology, and ultrastructure of a new phagotrophic nanoflagellate are described: Cryothecomonas aestivalis Drebes, Kühn \& Schnepf sp. nov. During summer and autumn it is frequently found in the North Sea phytoplankton feeding on the centric diatom Guinardia delicatula. The flagellate penetrates the diatom cell and phagocytizes the host cytoplasm by means of a pseudopodium that emerges from the posterior cell pole. The mature trophont gives rise to eight or more biflagellate swarmers which leave the emptied diatom frustule. Transmission electron microscopy revealed a delicate theca surrounding the swarmers. The pseudopodium protrudes through a gap in the theca. The cytostome consists of a membranous labyrinth. The mitochondria are of the tubular type. The two apically inserted flagella are heterodynamic and of unequal length. They are smooth, and their basal bodies are surrounded by satellites and fibrous strands ("transitional fibres" sensu Thomsen et al., 1990). In the trophonts and dividing flagellates the transition region between the flagellum and the basal body ends apically with a massive transitional cylinder instead of distinct microtubules, and is surrounded by a funnel of the theca. The nuclear envelope disintegrates during mitosis. Due to the fine structural details the new flagellate is placed in the genus Cryothecomonas Thomsen et al., a genus of still uncertain position.
\end{abstract}

\section{INTRODUCTION}

In the North Sea plankton, Guinardia delicatula (Cleve) Hasle is a common centric diatom (Drebes, 1974) and, especially in summer, one of the prominent primary producers in the phytoplankton of the German Bight. For the past 100 years the species was commonly known as Rhizosolenia delicatula Cleve, but recently it has been transferred to the genus Guinardia H. Peragallo by Hasle \& Syvertsen (1996). A careful in vivo inspection of freshly collected plankton samples as well as of raw cultures revealed that this diatom is frequently attacked by a hitherto undescribed flagellate, which invades the frustule and phagocytizes the protoplast. We studied the vegetative life cycle of this flagellate, especially its mode of food uptake, and its ultrastructure. As a result our new flagellate is assigned to the genus Cryothecomonas, which has recently been described by Thomsen et al. (1990). C. aestivalis sp. nov. belongs to the parasitic/parasitoidic 
nanoflagellates, to which little attention has previously been paid. Meanwhile, however, there is increasing evidence that acting as parasites or predators they can considerably affect the dynamics of phytoplankton populations (Kühn et al., 1996).

\section{MATERIALS AND METHODS}

For this study, the flagellate Cryothecomonas aestivalis was isolated in summer (August 1993 and 1994) from littoral plankton samples collected in the Wadden Sea near List/Sylt (German Bight, North Sea). The clones were grown in small Petri dishes, supplied with the F/2 medium (Guillard \& Ryther, 1962), and normally kept at $16^{\circ} \mathrm{C}$ under a 14:10 h light:dark regime, together with the host diatom, Guinardia delicatula (Cleve) Hasle. Two or three times per week the flagellates were transferred to a new Petri dish containing $G$. delicatula.

For live observations by light microscopy, we used Leitz sea-water immersion objectives. Cytochalasin D was used to affect the actomyosin system during infection. The agent was dissolved in dimethyl sulfoxide, and the stock solution diluted with the culture medium to a final concentration of $5 \mu \mathrm{g} \cdot \mathrm{ml}^{-1}$.

For transmission electron microscopy, we used a Philips SM 10. Cultures with infected diatoms and free flagellates were centrifuged and embedded in $3 \%$ Sea Prep agarose (Biozym, Hameln, Germany) (Reize \& Melkonian, 1989). They were then prefixed with $2 \%$ glutaraldehyde in $\mathrm{F} / 2$ medium, rinsed, and postfixed with $2 \% \mathrm{OsO}_{4}$ in the same medium. Alternatively, we used $2 \%$ glutaraldehyde in cacodylate buffer $(0.2 \mathrm{M}$, $\mathrm{pH} 7.2$, plus $0.25 \mathrm{M}$ saccharose), and subsequently $2 \% \mathrm{OsO}_{4}$ as fixatives. After rinsing with decreasing concentrations of saccharose we embedded the specimens in Sea Prep agarose. Both samples were dehydrated in an acetone series and embedded in Spurr's resin.

\section{RESULTS}

\section{Occurrence}

Cryothecomonas aestivalis was discovered in plankton samples off Helgoland (North Sea) in July 1970, and again recognized in August 1993 and in summer 1994 in plankton samples collected in the Wadden Sea near List/Sylt. During the main occurrence of the flagellate, the water temperatures ranged between $14-20^{\circ} \mathrm{C}$.

So far, C. aestivalis was only found on Guinardia delicatula, during the past years usually in August, occasionally as late as November, in samples collected from the Wadden Sea. Regarding the host range, feeding experiments with various other diatoms were not successful.

\section{Life cycle}

The vegetative life cycle of $C$. aestivalis comprises three stages: (1) the motile flagellates, outside and inside the host before food uptake; (2) the trophic (nutritive) phase, and (3) the phase of digestion and cell division.

The colourless flagellates (Figs 1,46) are oblong to oval, 9-12 $\mu \mathrm{m}$ long and 4-5 $\mu \mathrm{m}$ wide. Two heterodynamic flagella of unequal length are inserted apically, one being anteriorly directed and up to $15 \mu \mathrm{m}$ long, and the other one posteriorly and up to $25 \mu \mathrm{m}$ 
long. Both flagella are shorter during the trophic phase and in immature flagellates. The relatively large nucleus lies in the apical region of the cell. Flagellates in the motile phase are hyaline and contain only a few refractive bodies.

The flagellate swims slowly, sometimes sliding, but usually slightly tumbling in large curves. When it approaches a G. delicatula chain, the curves become narrower, and eventually it moves by gliding along the surface of the chain, while scanning it with the apex of the anterior flagellum. Finally, it attaches with a pseudopodium emerging from the posterior pole to one of the diatom cells (Fig. 2), generally close to the suture between valva and cingulum. Becoming slightly ameboid it squeezes into the interior of the diatom frustule, inserting the posterior pole first (Fig. 3). For some minutes, the flagella remain outside when the cell body has already entered the diatom (Fig, 4), but eventually they are also drawn inside. Presumably, they become shorter at the same time, for the flagellate inside the frustule has only very short flagella which are difficult to detect in the light microscope. The whole invasion process takes 5-10 min. Multiple infections are possible, especially under culture conditions. Only vegetative cells of $G$. delicatula, but no sexual stages (gametes, zygotes), are invaded by the flagellate.

Frequently, after having entered the diatom cell, the $C$. aestivalis cell migrates into a corner of a valva (Fig. 5). The diatom protoplast plasmolyzes at first locally, and after $2-3 \mathrm{~h}$ the $C$. aestivalis cell, surrounded by a larger, empty space, starts feeding.

The trophic phase begins with the emergence of a pseudopodium at the posterior pole of the cell. Portions of the diatom protoplast, frequently consisting of a chloroplast and some cytoplasm, are gradually phagocytized (Fig. 6) and individually included in a food vacuole, a process which takes about $10 \mathrm{~min}$ in each case. The phagocytizing pseudopodium varies in shape, at times being long (Fig. 7) or short and broad (Fig. 8), and contracts rhythmically during the ingestion phase.

The trophont grows considerably, filling a large part of the diatom cell when the cytoplasm has been completely ingested. It then bears two short flagella, and several food vacuoles fill the posterior region of the cell (Fig. 9). During digestion the chloroplasts change colour, becoming brown. Depending on the size of an attacked diatom cell the globular, mature trophont may become more than $20 \mu \mathrm{m}$ long and $10 \mu \mathrm{m}$ wide. The food uptake finishes early when the membrane of the Guinardia protoplast is ruptured and the remaining cell organelles disintegrate.

About $4 \mathrm{~h}$ after the infection, the division phase begins with the formation of another pair of flagella. The resulting daughter cells (Fig. 10) divide after further $4 \mathrm{~h}$ (Fig. 11), and again $2 \mathrm{~h}$ later a third division (and later further ones) may follow. The food vacuoles are equally distributed among the daughter cells. Defecation of brown granular material (fecal bodies) takes place before the last cell division (Fig. 12) and is not related with the cytokinesis. The number of offspring depends on the amount of ingested food. As a result there are usually 8 (up to 32) swarmers. The offspring number is lower in small Guinardia cells or after multiple infections.

The new, slightly ameboid flagellates slip with their posterior pole foremost into the frustule (Fig. 13), presumably at the sutures between valva and cingulum, or between the overlapping epi- and hypocingulum. They are soon capable of invading a new diatom cell. The whole vegetative life cycle takes $18-20 \mathrm{~h}$. The brown fecal bodies inside the otherwise empty Guinardia cell remain as the vestiges of the preceding attack by $C$. aestivalis (Fig. 14). The cell chains of the diatom do not get fragile when attacked by 


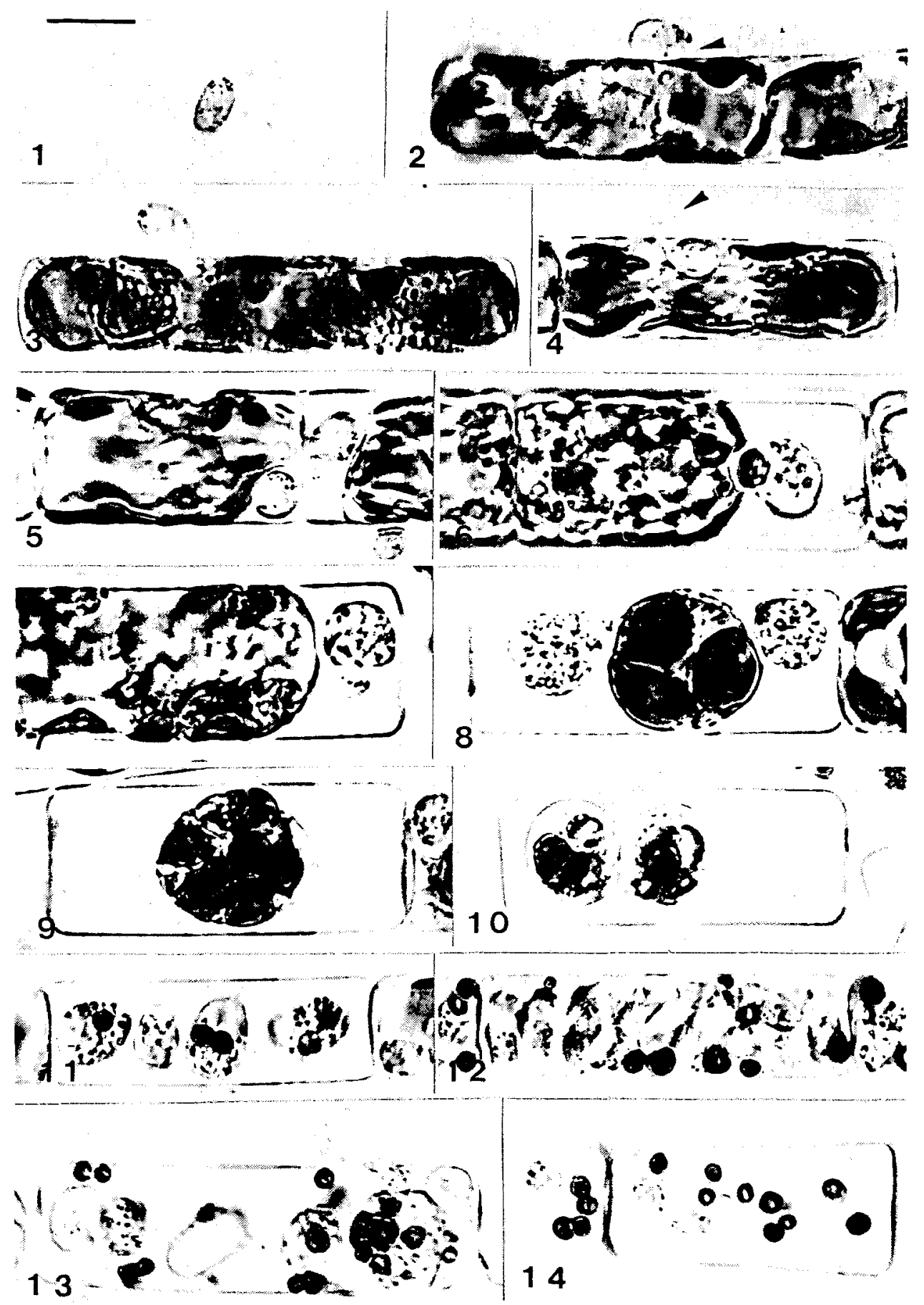


Cryothecomonas. Even when all protoplasts are phagocytized (Figs 11-14), both diatom cells and cell chains remain intact for a long time.

Occasionally, in old cultures, finely granulated cyst-like cells of Cryothecomonas are formed inside the diatom frustules (not illustrated).

A treatment with cytochalasin $\left(5 \mu \mathrm{g} \cdot \mathrm{ml}^{-1}\right)$ slows down the movement of the unattached swimming flagellates within $20 \mathrm{~min}$ and stops it nearly completely after $35 \mathrm{~min}$, whereas another unidentified, non-infective flagellate (Cafeteria?), a contaminant in the same culture, is not affected in its motility. Under the influence of cytochalasin new infections have not been observed; some Guinardia cells become slightly plasmolyzed.

\section{Fine structure}

Using electron microscopy, we investigated mainly cells of C. aestivalis in the trophic and the reproductive phase which were enclosed in Guinardia frustules. The fine structure of the cells differed slightly in some details, mainly due to variations during development.

A survey of a cell at the end of the trophic phase is shown in Figure 15. The nucleus lies close to the basal bodies of the flagella which are inserted apically. It is lens-shaped and highly lobed. The prominent nucleolus is associated with bands of dense heterochromatin. Occasionally, there are nuclei with two nucleoli. Dense heterochromatin also forms a conspicuous, peripheral layer at the nuclear envelope (see Figs 15, 26, 39, 43). The outer membrane of the nuclear envelope is studded with ribosomes (Fig. 26). The cell in Figure 15 contains several food vacuoles at different stages of digestion. The contents of one resembles the fecal body shown in Figure 16 and seems to be largely composed of lipids. The amount of osmiophilic droplets in the cytoplasm is especially high at the end of the trophic phase.

The flagellates are generally surrounded by a close-fitting, delicate theca. It consists of an electron-dense, $8 \mathrm{~nm}$ thick basal layer which is covered with a $50 \mathrm{~nm}$ thick fuzzy coat (Figs 17,19). A regular substructure in the form of a striation could not be detected. The theca is often incompletely preserved or even nearly completely absent, especially in maturing trophonts and dividing cells. In the flagellar pit (Fig. 19) the theca is modified, and it is absent at the cytostome (see below).

The mitochondria of $C$. aestivalis have small cristae, and belong to the tubular rather than to the vesicular-discoid type (Fig. 18). There are a few, small dictyosomes (Fig. 17), scattered mainly in the anterior region of the cell.

Figs 1-14. Cryothecomonas aestivalis, live cells. Scale bar: $10 \mu \mathrm{m}$. 1: Free-motile flagellate. 2 : Flagellate forming a pseudopodium (arrowhead) to attach to the surface of a host cell (Guinardia delicatula). 3: Flagellate squeezing, with its posterior end first, into the host cell. 4: Flagellate having entered the diatom, with the flagella still outside (arrowhead). 5: Two Cryothecomonas cells under the valvae of their host cells. 6: Young trophont engulfing a chloroplast. 7: Trophont with a very long pseudopodium. 8: Double infection, left trophont with distinctly recognizable flagella and a short, broad pseudopodium. 9: Trophont at the end of the nutritive phase; note the two short flagella. 10: Two daughter cells after the first division. 11: Four cells after the second division; note their short flagella. 12: Many swarmers at the final stage of reproduction; numerous fecal bodies (dark), set free before the last division, fill the host frustule. 13: A flagellate without digestion vacuoles leaves the diatom frustule; fecal bodies are left behind. 14: Most of the swarmers have left the frustule; fecal bodies remain as vestiges of a preceding attack by Cryothecomonas 


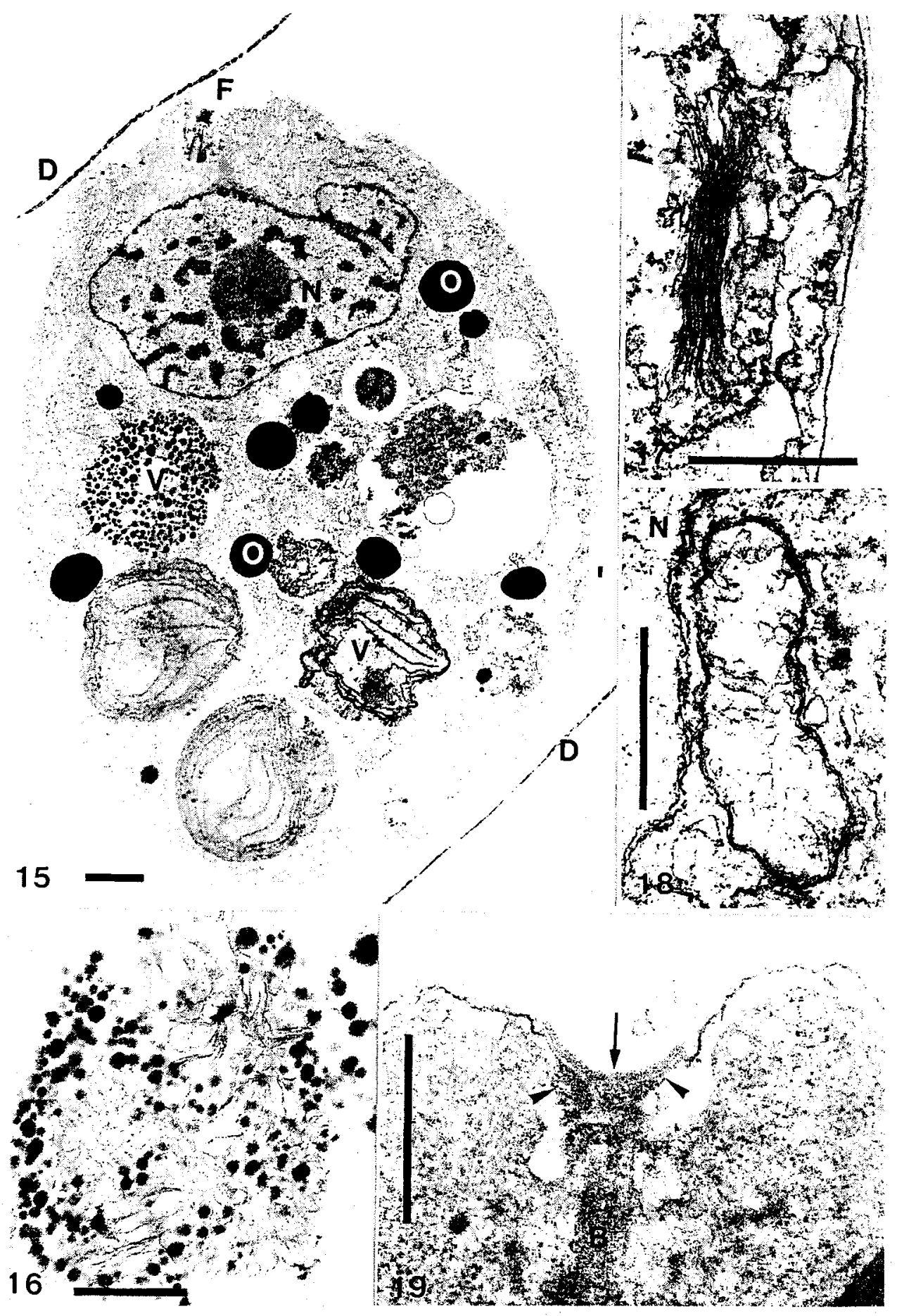



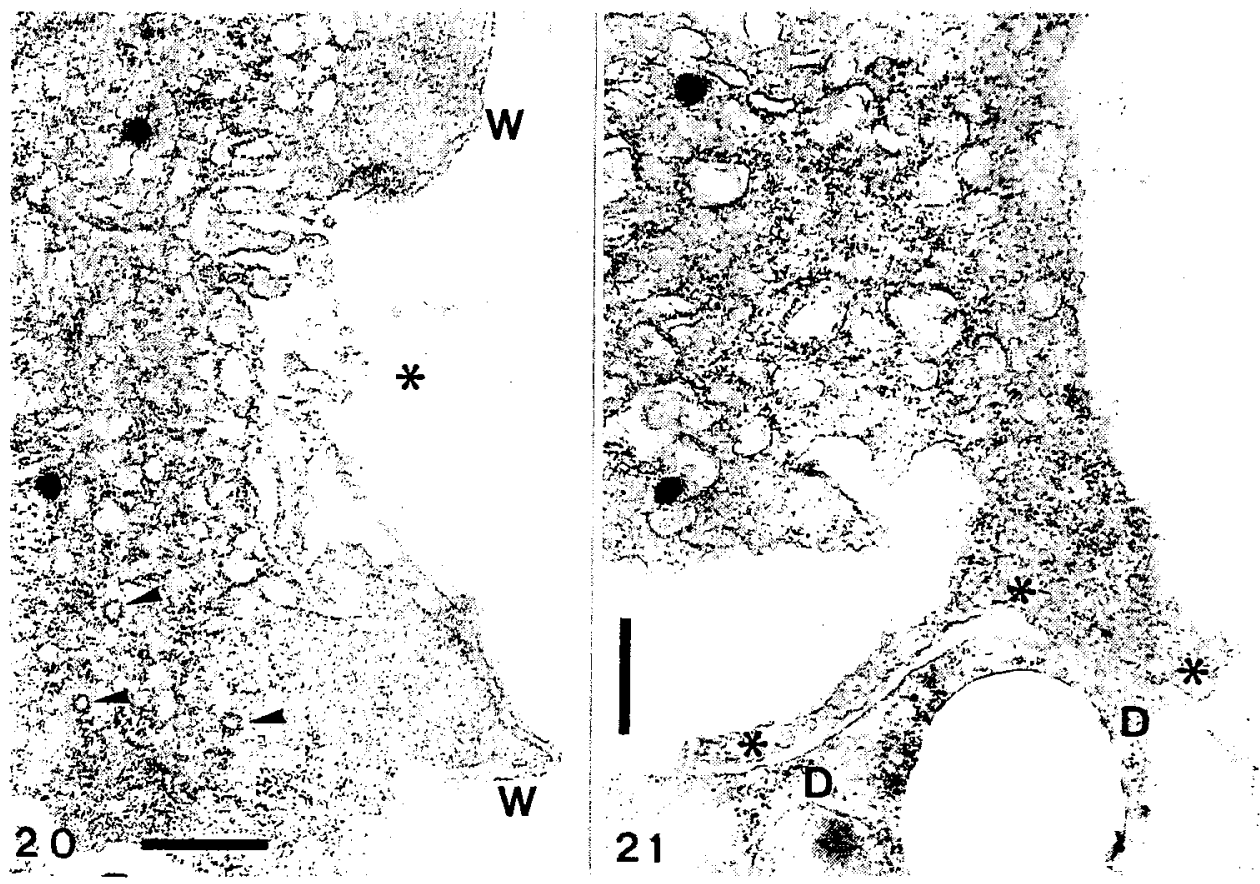

Figs 20, 21. Cryothecomonas aestivalis, transmission electron microscopy: food uptake. Scale bar: $0.5 \mu \mathrm{m} .20$ : Retracted pseudopodium. W, theca absent in the cytostome region (asterisk). Cytostomal cytoplasm highly vesiculated, with coated vesicles (arrowheads), and many invaginations and protrusions. 21: Protruded pseudopodium (above) in close contact with the diatom cytoplasm D, numerous vesicles, in part with membranous contents, fibrillar-granular cytoplasm in the contact zone (asterisks)

In the basal region of the trophonts, where the food is phagocytized, the theca has a gap. The cell periphery consists here of a labyrinth of cytoplasmic processes and invaginations - the cytostome in the terminology of Thomsen et al. (1990) (Fig. 20). It can be transformed into the pseudopodium as shown in Figure 21. The cytoplasm of the pseudopodium and of the cytostome area is highly vesiculated. Many vesicles have membranous contents, and some of them are coated. In the region where the pseudopodium is in close contact with the diatom protoplast, it is vesicle-free and has a granularfibrillar appearance.

Figs 15-19. Cryothecomonas aestivalis, transmission electron microscopy. 15: Flagellate at the end of the trophic phase. $V$, several food vacuoles with contents at different stages of digestion; $F$, apical flagellum; $N$, nucleus with nucleolus; $O$, osmiophilic bodies; $D$, part of the diatom frustule. Scale bar: $1 \mu \mathrm{m}$. 16: Fecal body; compare with Fig. 15. Scale bar: $0.5 \mu \mathrm{m}$. 17: Cryothecomonas theca consisting of two layers, and to the left a dictyosome. Scale bar: $0.5 \mu \mathrm{m}$. 18: Mitochondrium; N, nucleus. Scale bar: $0.5 \mu \mathrm{m}$. 19: Cell wall and its modification at the funnel in the flagellar pit, seen in tangential section, with the coarse sleeve as continuation of the cell wall (arrowheads) and the homogeneous cone (arrow); $\mathrm{B}$, basal body in tangential section. Scale bar: $0.5 \mu \mathrm{m}$ 
The flagella are both smooth; one of them may be thicker at the basis, immediately over a conspicuous funnel of the theca. A flagellar rod with a regular substructure could not be detected within the flagellar swelling.

Each fully developed flagellum inserts separately in a small pit, and each is surrounded by a funnel consisting of two parts (see Figs 19,22-25, 26, 27, 35 and the scheme, Fig. 31). The lower part of the funnel, the "sleeve", is continuous with the inner dense layer of the theca, when the latter is present, and has a relatively coarse structure. It surrounds the upper part, the "cone", which is densely homogeneous in structure.

The transition region between the flagellum and the basal body varies in structure, presumably in connection with the development of the cell. It begins at the level of the funnel. Here the flagellum becomes thinner (Figs 26, 27); the two central microtubules end (Fig. 27), and the peripheral doublets of the axoneme become indistinct, merging into a dense, massive, $35 \mathrm{~nm}$ broad "transitional cylinder". The latter appears nearly homogeneous in cross sections through the flagellum, and is in close contact with the plasma membrane (Figs 22-27). Longitudinal tangential sections through the flagella reveal the transitional cylinder to consist of a stack of 2-7 subrings, visible as a fine striation with a spacing of $7 \mathrm{~nm}$ (Figs 26, 32). In flagella with a basal thickening the transitional cylinder is generally thicker than in non-thickened flagella. Below the transitional cylinder 9 peripheral structures reappear (Figs 24,25). Near the ground of the flagellar pit they are massive, about triangular in cross section, and surround a central dense plug (Fig. 25). The structure of the basal body proper is typical - with 9 microtubular triplets (Fig. 29). Basal body and transitional region are about $0.5 \mu \mathrm{m}$ long.

The two basal bodies form an angle of $70^{\circ}-90^{\circ}$ (Fig. 30), and the insertion sites of the flagella are separated by a small papilla (Fig. 39). The proximal ends of the basal bodies show a typical cartwheel structure (Figs 30,38 ), and are connected by a short striated band (Figs 30,36, and the scheme, Fig. 37). The basal bodies are surrounded by many electron-dense satellites of variable size and shape (Figs 26, 28-30), which come in close contact with the microtubular triplets in the proximal region of the basal bodies. The

Figs 22-30. Cryothecomonas aestivalis, transmission electron microscopy: flagella and flagellar bases of trophonts and cells in the division phase. Scale bar: $0.5 \mu \mathrm{m}$. Figs 22-25. Series of cross sections through a transition zone level with the flagellar pit, from distal to proximal. 22: Nine peripheral elements are still visible; the funnel consists here mainly of the cone (arrow). 23: A massive, homogeneous transitional cylinder instead of nine peripheral elements. 24: Nine peripheral elements are indistinctly visible. Funnel with cone (arrow) and sleeve (arrowhead). 25: Nine triangular peripheral elements and a central plug at the base of the flagellar pit. The funnel is absent here. 26: Flagellum with basal swelling. Funnel with cone (arrows) and sleeve (arrowheads), transitional cylinder (big arrowhead) in tangential section showing fine striation. $R$, flagellar root; $\mathbf{s}$, satellites; group of microtubules in the apical papilla (double arrowheads); $N$, nucleus with ribosomes close to the nuclear envelope. 27: Unswollen flagellum and basal body. Transitional cylinder less high than in Fig. 26. Funnel with cone (arrows) and sleeve (arrowheads) which is in connection with the insufficiently preserved cell wall. Figs 28-30. Series of cross-sections through a pair of basal bodies, from distal to proximal. 28: Cross-section through basal body 1 at the base of the flagellar pit (asterisk). Radial "transitional fibres" to satellites (s). S: satellites of basal body 2. 29: Ring of satellites (s), surrounding basal body 1 and partly connected by "transitional fibres" with the microtubular triplets. S: satellites of basal body 2. 30: Basal body 1 with cartwheel structure, basal body 2 in longitudinal section, surrounded by satellites (S) in funnel-like arrangement. A striated band (white arrow) connects the proximal ends of the two basal bodies. Flagellar funnel with cone and sleeve. 


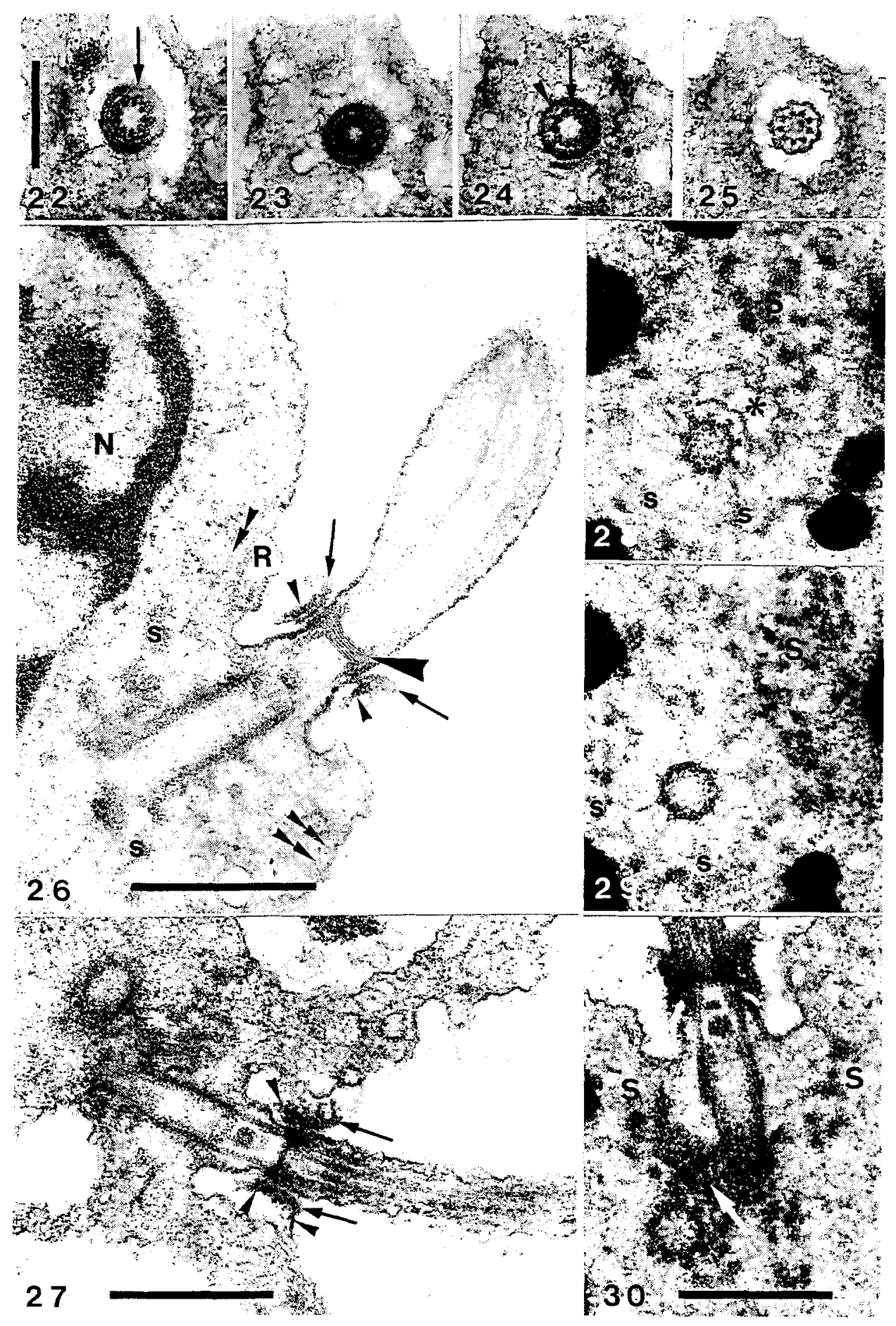




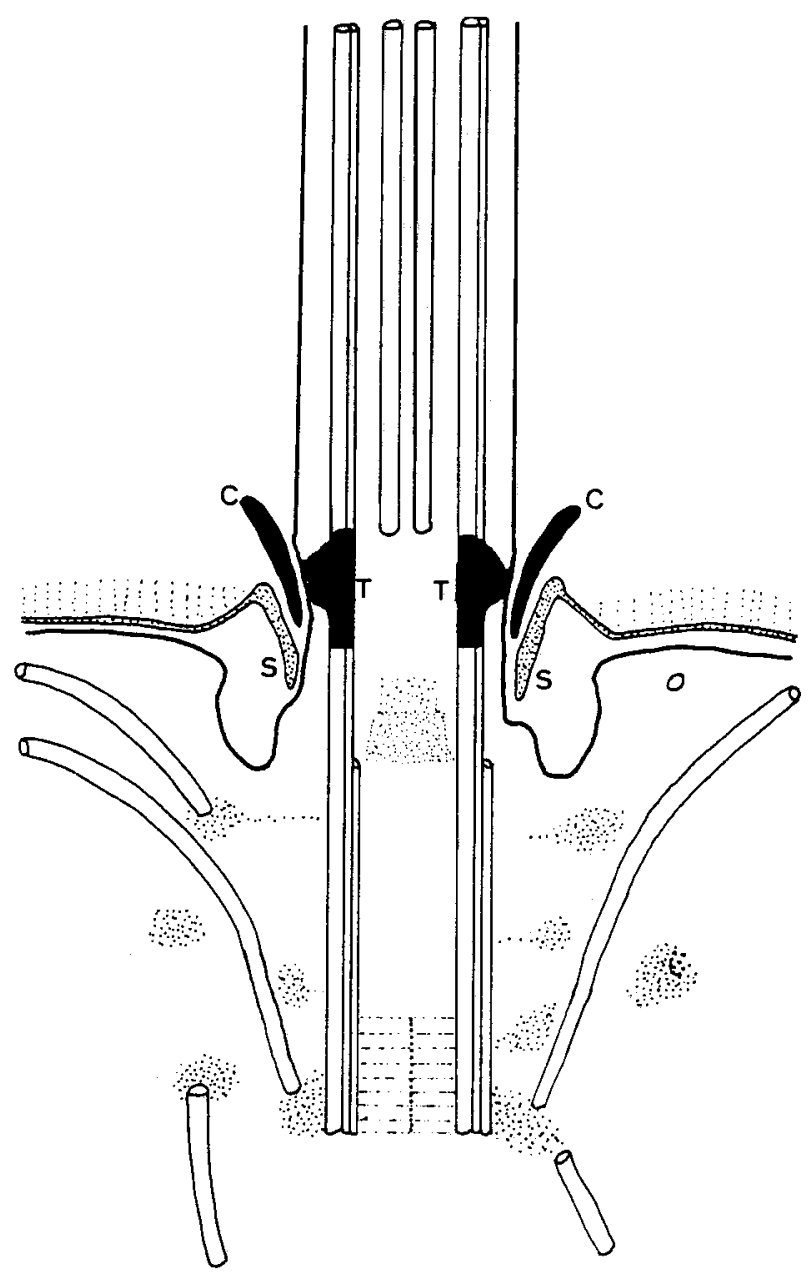

Fig. 31. Cryothecomonas aestivalis, scheme of flagellar base at a stage containing numerous microtubules. Funnel with cone (C) and sleeve (S) level with the transitional cylinder (T) and satellites as initiation sites of microtubules

Figs 32-36. Cryothecomonas aestivalis, transmission electron microscopy: flagellar root and division. Scale bar: $0.5 \mu \mathrm{m}$. 32: R, microtubular flagellar root at the basal bodies. Funnel, transitional cylinder (white arrowhead) with fine striation; $N$, nucleus. 33: Distal part of the microtubules of the flagellar root (arrowheads) running along the plasma membrane. 34: Flagellar pit with two flagella, cross sectioned at the level of the transitional cylinder. This cell has another pair of flagella nearby. 35 : Basal body associated with many microtubules (arrowheads) running in diverse directions, some microtubules originating near satellites. 36: Two pairs of flagella, each with a striated connecting band (arrows) and surrounded by many microtubules (arrowheads) 


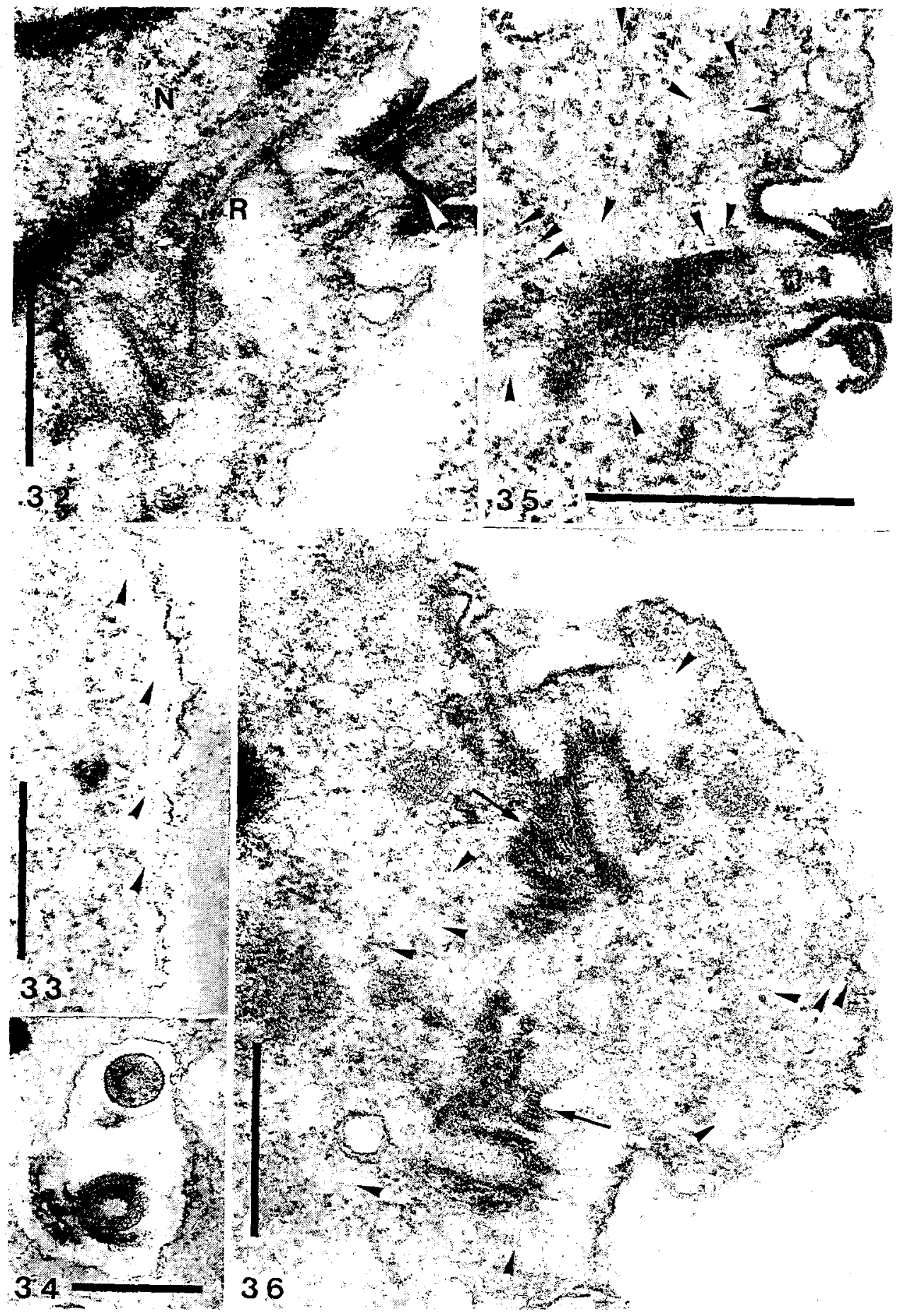




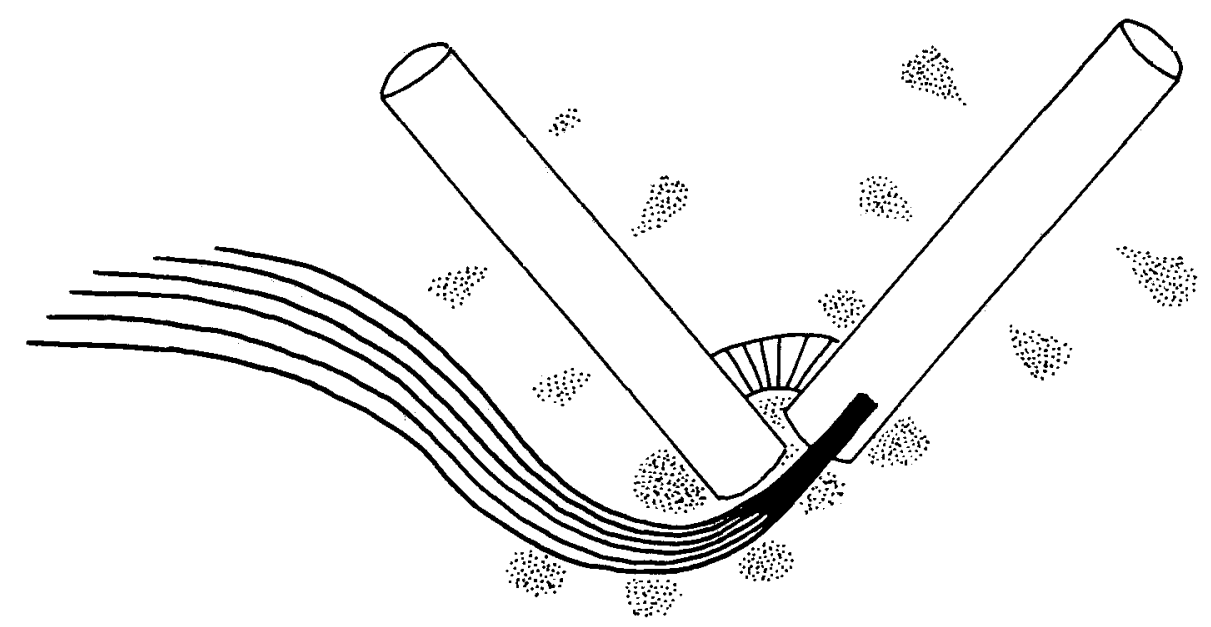

Fig. 37. Cryothecomonas aestivalis, scheme of pair of flagellar bases with microtubular root and striated connecting band

satellites of the two basal bodies merge here (Fig. 30). More apically the satellites are arranged in the form of a cylinder or cone. Some of them are connected by radial strands ("transitional fibres" sensu Thomsen et al., 1990) with the triplets of the basal body (Figs $28,29)$.

A microtubular flagellar root originates in the region where the two basal bodies lie close together (Figs 26, 32, and the scheme, Fig. 37). It consists of a band of microtubules which are embedded in an electron-dense matrix. It is proximally associated with satellites, and runs to the cell surface where the matrix is reduced, and the microtubules diverge to accompany the plasma membrane in the apical part of the cell (Fig. 33). The apical papilla contains another small group of microtubules (Fig. 26). Other cytoskeletal microtubules originate near the satellites, generally between the basal bodies (Fig. 35). They differ highly in number and orientation. Some of them run also toward and along the plasma membrane, others toward or along the nucleus. There are cells which seem to contain only very few of these microtubules (Figs 27,29 ), while other cells, especially those in the division phase, have many of them, often in a seemingly irregular arrangement (Fig. 36).

Mitosis and cytokinesis are initiated by the formation of a new pair of flagella. Initially, the new pair is situated in a common flagellar pit (Fig. 34). Many microtubules radiate from the flagellar bases when the pairs begin to move apart (Figs 36, 38). Most of

Figs 38-41. Cryothecomonas aestivalis, transmission electron microscopy: division. Scale bar: $1 \mu \mathrm{m}$. 38: Two pairs of basal bodies moving apart and connected by a fibrillar band (arrows). The upper pair reveals the cartwheel structure in cross-section and longitudinal section. Microtubules (arrowheads) radiate from the basal bodies, but are absent in the region between the two pairs. $R_{1}$, flagellar root; $N$, nucleus. 39: Flagellate with four flagella or basal bodies, respectively; in this section not all of them are visible at each cell pole $(F)_{;} N$, lobed nucleus. 40: Nucleus in metaphase stage. $D$, part of the diatom frustule. 41: Same metaphase as in Fig. 40. Bundles of spindle microtubules (arrowheads) 

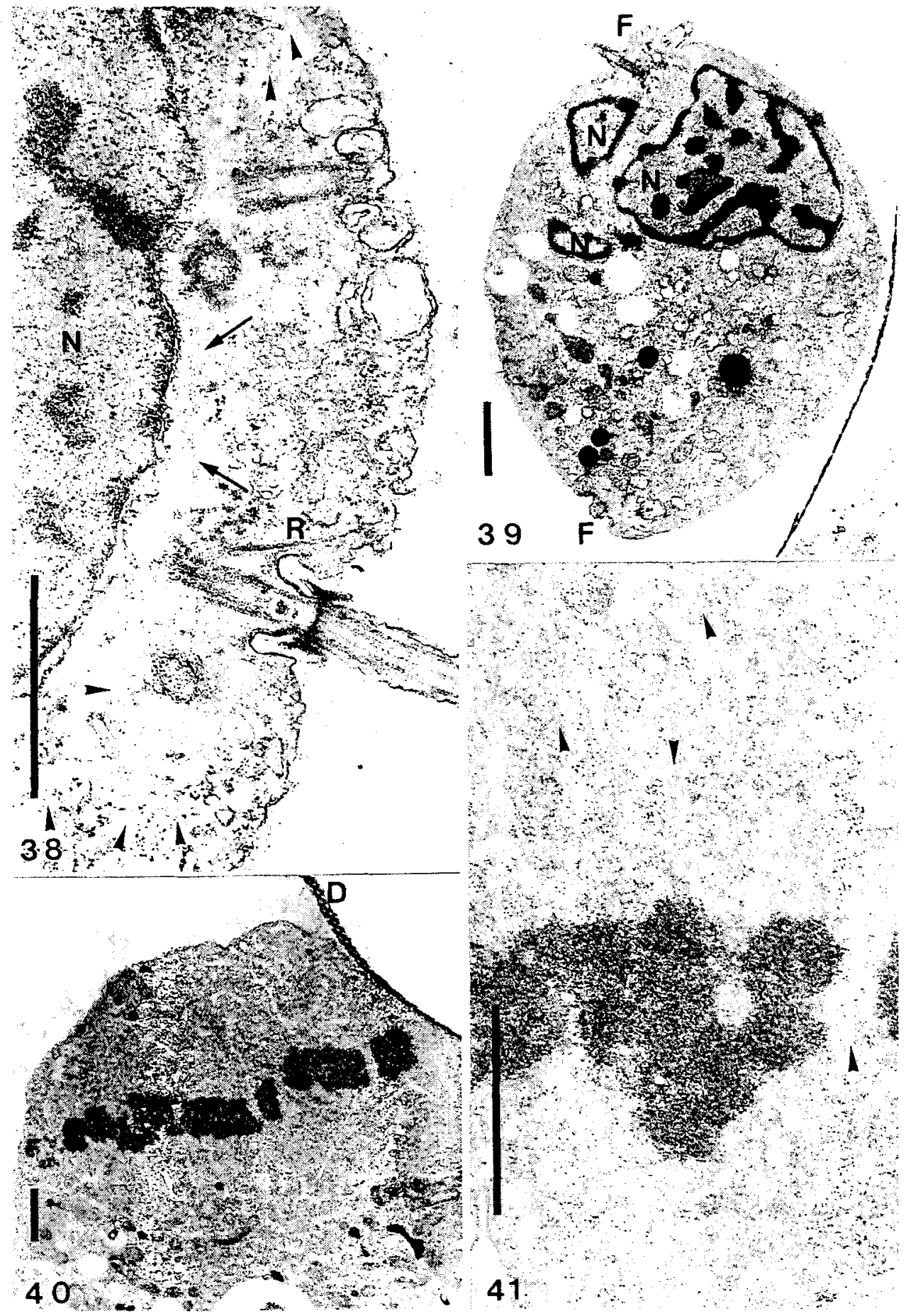
them run peripherally, some also into the interior of the cell, and they do not appear to be well ordered. Between the separating pairs of basal bodies microtubules are largely absent, but they are transiently connected by a fibrous band (Fig. 38). Later, the flagella are found at opposite poles of the cell (Fig. 39). At this stage, they are already associated with new basal bodies, when the cells are about to continue the divisions.

During prophase the nuclear envelope disintegrates completely. Figure 40 shows a cell in metaphase, with the chromosomes lined up in the equatorial plate. At higher magnification the spindle microtubules can be seen (Fig. 41). Only diffuse kinetophores seem to be present. At early telophase the nuclear envelope begins to reconstitute at the periphery of the chromosome mass, while polar spindle microtubules remain initially present between the two daughter nuclei (Fig. 42).

Cells with two nuclei are often found, indicating that there is a certain time span between mitosis and cytokinesis. The cell division begins with an accumulation of vesicles in the region of the developing furrow, many of them with membranous contents (Fig. 43). The narrowing connecting strand between the two daughter cells is traversed by many microtubules (Figs 44,45 ). In contrast to a midbody a distinct overlap zone does not seem to be present here. A peripheral contractile ring is not always clearly visible. It is best seen in tangential sections (Fig. 45).

\section{DISCUSSION}

There can be no doubt that the present flagellate is closely related with Cryothecomonas Thomsen et al., a genus comprising marine, free-living, phagotrophic flagellates. Unlike Thomsen et al. (1990), we had mainly trophontic and subsequent reproductive stages inside the diatom frustule at our disposal. Nevertheless, many characters of $C$. aestivalis are completely or largely identical with those of the four species described by Thomsen et al. (1990), which also differ from one another in some details.

Similarities and slight differences are:

(1) The shape of the cell with an apical pair of smooth flagella of different length, each inserted in its own flagellar pit and separated by a small apical papilla; further the position and size of the food vacuoles.

(2) The position of the nucleus close to the flagellar bases, the nuclear structure with the conspicuous heterochromatin along the nuclear envelope and in the form of irregular bands throughout the interior of the nucleus, and a big nucleolus.

(3) The presence of a close-fitting theca which differs somewhat in the four species of Thomsen et al. (1990). In our flagellate it consists of a thin electron-dense inner layer, and a thicker, looser outer layer which is, in contrast to the above mentioned species, not regularly ridged. A further deviation is the frequently insuffient preservation of the theca, perhaps because it is modified during the trophic and reproductive phase. Obvious

Figs 42-45. Cryothecomonas aestivalis, transmission electron microscopy: division. Scale bar: $0.5 \mu \mathrm{m}$. 42: Nucleus at telophase stage. Reconstitution of the nuclear envelope (asterisks), spindle microtubules (arrowheads). 43: Beginning of cytokinesis. Accumulation of vesicles in the division furrow. N, nucleus. 44: Final stage of cytokinesis. The narrowing connecting strand is traversed by many microtubules, cytoplasm vesiculated, fibrillar ring indistinctly visible (arrowheads). 45: Final stage of cytokinesis. Tangential section through the narrowing connecting strand reveals the fibrillar ring (arrows); microtubules 


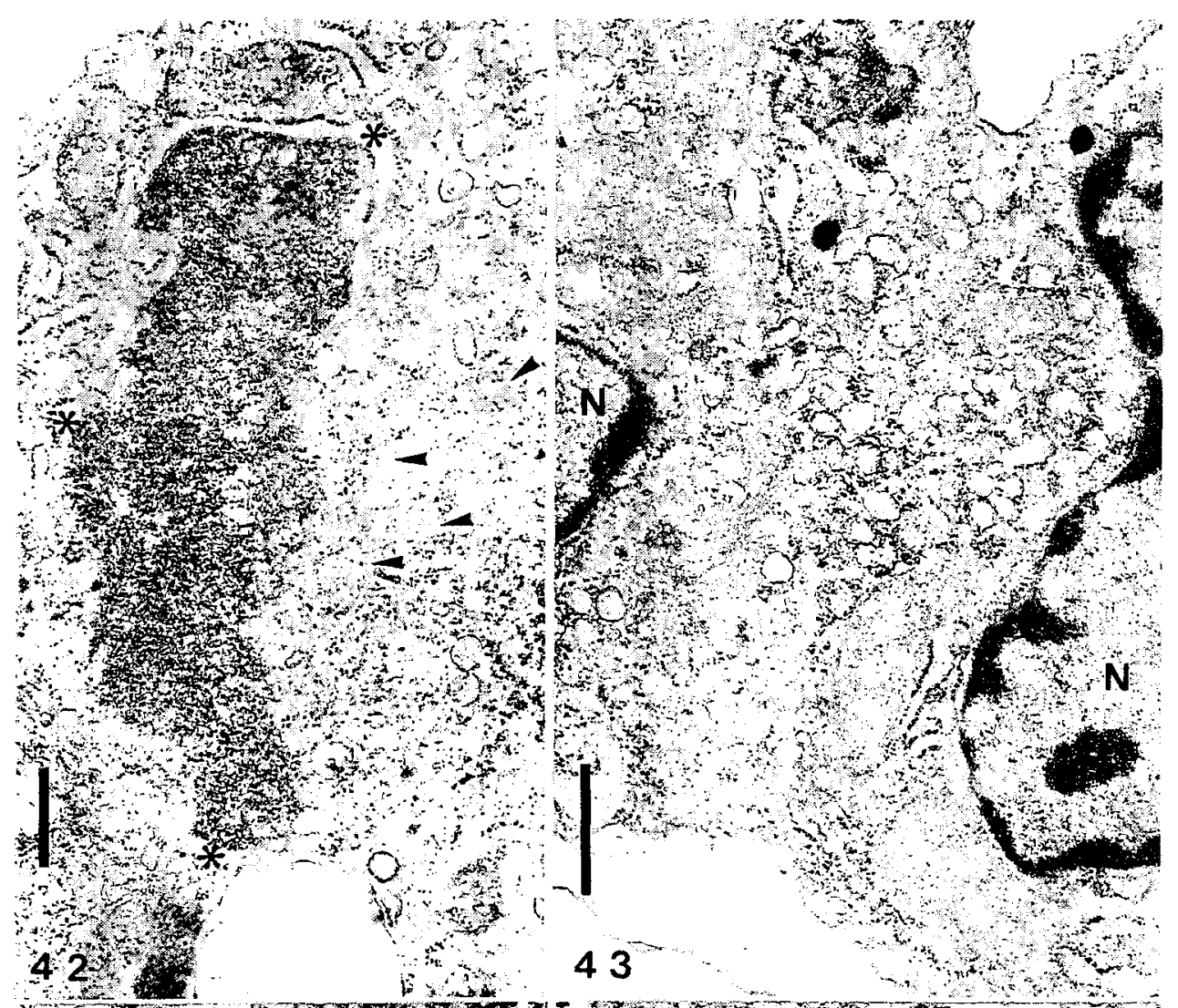

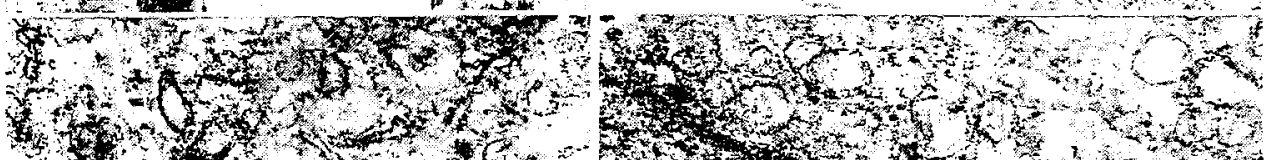

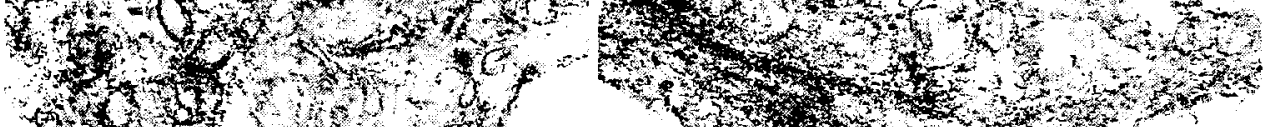

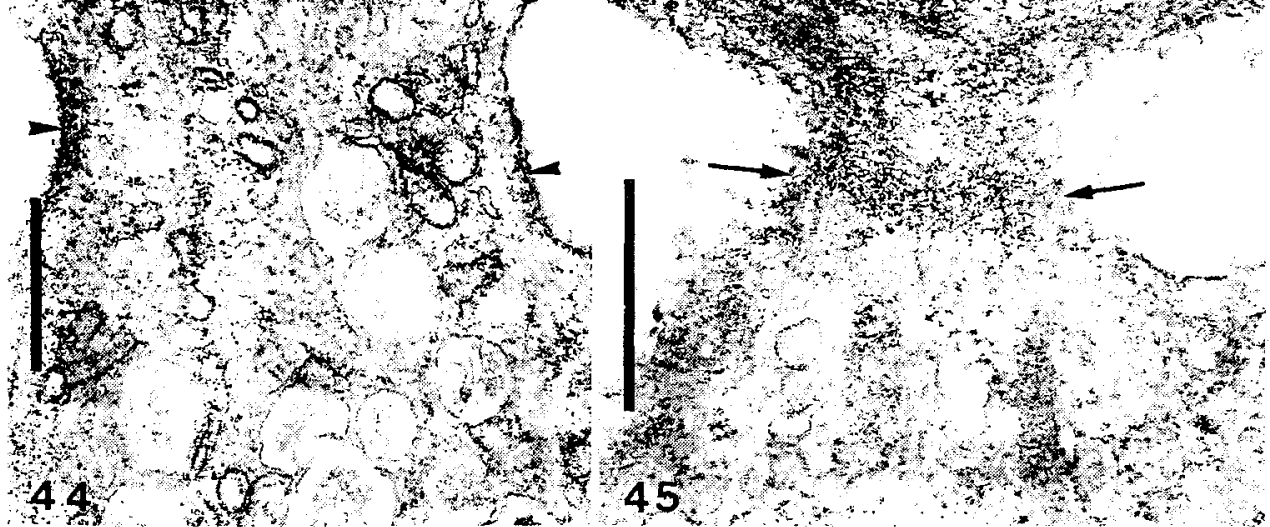


similarities between the species are the presence of a gap in the posterior part of the cell and, especially, the complicated structure of the funnel through which the flagella emerge.

(4) The thecal gap of all species is associated with a cytostome consisting of cytoplasmic invaginations and protrusions, and it can be transformed into a pseudopodium. The cytostomal cytoplasm is in every case filled with vesicles, in part with membranous contents, and contains an organelle-free area of fine granular-fibrillar appearance, presumably representing actomyosin complexes.

(5) The flagellar basal bodies and their surroundings with radial "transitional fibres" and "satellites" (electron-dense aggregations sensu Thomsen et al., 1990) are likewise very similar in all species. These electron-dense bodies are believed by Thomsen et al. (1990) to represent glycogen. Our micrographs rather suggest that they are proteinaceous and function as microtubule organizing centres in the phase of divison. According to Thomsen et al. (1990), the transition region of their species contains a transitional helix which is, however, indistinctly shown. Instead, we found in our species a massive transitional cylinder at the distal end of the transitional region. Because of the lack of exact data on the flagellar root system in the paper of Thomsen et al. (1990), these structures cannot be compared in detail with those of our flagellate. As far one can see, they seem to be similar. This applies also to the group of microtubules in the apical papilla.

(6) The mitochondria likewise belong to the same type in that they have indistinctly tubular cristae.

Compared with Cryothecomonas armigera, our species does not contain extrusomes, and also no muciferous bodies as for instance in $C$. vesiculata. Furthermore, we could not unambiguously identify lysosomes. It remains to be confirmed whether the "lysosomes" of Thomsen et al. (1990) are correctly characterized or are perhaps microbodies.

Major differences are the following:

(1) The adaptation to cold temperatures of the four species described by Thomsen et al. (1990), which seem to have a world-wide occurrence in sea ice biota, as in the Arctic, Antarctic, and the Baltic Sea (Ikävalko \& Thomsen, 1995). It is reflected in the name of the genus $(C r y o \ldots)$, but does not apply to our species, which occurs in late summer and autumn in the North Sea.

(2) Cryothecomonas aestivalis has a peculiar mode of nutrition and development: it invades specifically cells of Guinardia delicatula, and gradually phagocytizes the host cytoplasm.

(3) Presumably, only our species behaves as a "parasite", i. e., with an extended trophic phase followed by a series of cell divisions, as known from other "parasitic" flagellates (Gaines \& Elbrächter, 1987).

In conclusion, it seems justified to place our flagellate in the genus Cryothecomonas Thomsen et al., and to erect a new species, $C$. aestivalis.

The taxonomic position of Cryothecomonas is uncertain, as discussed in detail by Thomsen et al. (1990). Our studies provide only few new data which might be taxonomically relevant. The mitosis is an open orthomitosis in that the nuclear envelope disintegrates completely, i. e., it is of the evolved type (Raikov, 1994). During cell division, a bundle of microtubules remains in the narrowing connecting strand between the two sister cells. The transitional cylinder at the base of the (developing?) flagella is perhaps of 
additional significance in this respect. But these further characters are not yet sufficient to assign the genus with absolute taxonomic certainty. Molecular biological methods, which have been initiated, will be more informative.

The flexibility of the cell body and of the theca allows C. aestivalis to slip through the diatom frustule into the cell. This is done after the suitability of the host ceil as food source has been tested, obviously by the tip of the anteriorly directed flagellum. A similar behaviour is displayed by Pirsonia Schnepf et al., another flagellate feeding on diatoms (Schnepf et al., 1990). The attachment to the diatom frustule is perhaps not performed by the secretion of a sticky material but by the sucking force of the pseudopodium.

The entrance of the flagellate into the diatom cell and food uptake seems to be driven by the actomyosin system of the pseudopodium, as indicated by the inhibitory effects of cytochalasin $D$, and the presence of a fibrillar-granular cytoplasm in the area where the pseudopodium contacts with the host cytoplasm.

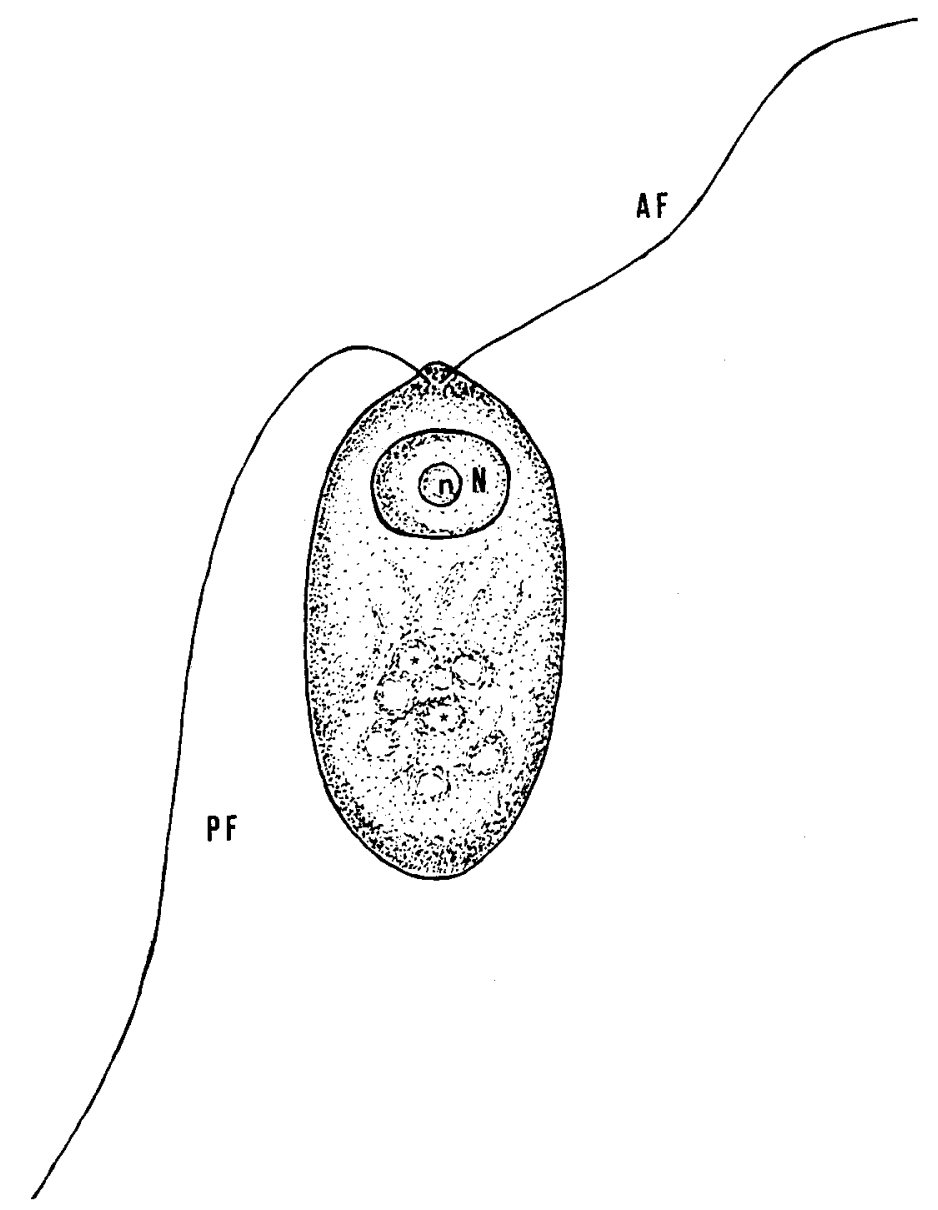

Fig. 46. Cryothecomonas aestivalis, sketch of a flagellate in the free, motile stage. AF, anteriorly directed flagellum; PF, posteriorly directed flagellum; $N$, nucleus; $n$, nucleolus; refractive granula (asterisks) 
The numerous vesicles in the cytostomal cytoplasm, many of them with membranous contents (see Daley et al., 1973, for phagocytizing Ochromonas) or with a coat, suggest an intensive membrane flow and a high turnover rate of membranes during food uptake. It can be expected that Golgi apparatus-derived vesicles deliver digestive enzymes into the phagosomes (Cole \& Wynne, 1974), but we did not observe a conspicuous activity of the relatively few dictyosomes during feeding and digestion, and were not able to identify primary lysosomes with certainty.

The cytostome of Cryothecomonas aestivalis differs from the cytostomes of most other phagotrophic flagellates in that it is not shaped by a distinct microtubular cytoskeleton (see the review by Radek \& Hausmann, 1994).

The ecology of $C$. aestivalis will be treated separately (Kühn, in prep.).

\section{Diagnosis}

Cryothecomonas aestivalis Drebes, Kühn \& Schnepf, sp. nov.

Colourless flagellates; in the free, motile stage, oblong to oval, 9-12 um long and 4-5 $\mu \mathrm{m}$ wide. Two apically inserted flagella. Anteriorly directed flagellum $15 \mu \mathrm{m}$ long; posteriorly directed flagellum up to $25 \mu \mathrm{m}$. Feeds on the marine planktonic diatom Guinardia delicatula. Flagellate penetrates the diatom frustule. Trophonts gradually phagocytize the host cytoplasm by means of a pseudopodium, which emerges posteriorly through a gap in the theca. Theca delicate, consisting of two layers, occasionally lacking. Trophonts and division stages with shortened, in part basally thickened flagella, and a massive transitional cylinder that lacks a distinct transitional helix. Extrusomes and muciferous bodies absent. Mature trophonts give rise to 8-32 new flagellates (swarmers). Defecation before the last division.

Distribution: Plankton of the North Sea, July-November.

Type locality: Wadden Sea at List/Sylt, German Bight (North Sea).

Holotype: Figs 15, 46.

Etymology: Species name refers to the main occurrence of the flagellate in summer.

Acknowledgements. We are grateful to Ms H. Halliger and Ms S. Gold for technical assistance, to Dr. M. Elbrächter for valuable discussions, and to the Deutsche Forschungsgemeinschaft for financial support. This is contribution No. 1055 of the Alfred-Wegener-Institut für Polar- und Meeresforschung, Bremerhaven.

\section{LITERATURE CITED}

Cole, G. T. \& Wynne, M. J., 1974. Endocytosis of Microcystis aeruginosa by Ochromonas danica. - J. Phycol. 10, 397-410.

Daley, R. J., Morris, G. P. \& Brown, S. R., 1973. Phagotrophic ingestion of a blue-green alga by Ochromonas. - J. Protozool. 20, 58-61.

Drebes, G., 1974. Marines Phytoplankton. Thieme, Stuttgart, $186 \mathrm{pp}$.

Gaines, G. \& Elbrächter, M., 1987. Heterotrophic nutrition. In: The biology of dinoflagellates. Ed. by F. J. R. Taylor. Blackwell, Oxford, 224-268.

Guillard, R. R. L. \& Ryther, J, H., 1962. Studies on marine phytoplankton diatoms. 1. Cyclotella nana Hustedt and Detonula confervacea (Cleve) Gran. - Can. J. Microbiol, 8, 229-239. 
Hasle, G. R. \& Syvertsen, E. E., 1996. Marine diatoms. In: Identifying marine diatoms and dinoflagellates. Ed. by C. R. Tomas. Acad. Press, San Diego, $598 \mathrm{pp}$.

Ikävalko, J. \& Thomsen, H. A., 1995. Baltic sea ice biota (March 1994): remarks on the occurrence and abundance of Cryothecomonas armigera (Protista incerta sedis) and C. scybalophora. - Eur. J. Protistol. 31, 113.

Kühn, S. F., Drebes, G. \& Schnepf, E., 1996. Five new species of the nanoflagellate Pirsonia in the German Bight, North Sea, feeding on planktic diatoms. - Helgoländer Meeresunters. 50, 205-222.

Radek, R. \& Hausmann, K., 1994. Endocytosis, digestion, and defecation in flagellates. - Acta Protozool. 33, 127-147.

Raikov, I. B., 1994. The diversity of forms of mitosis in protozoa: a comparative review. - Eur. J. Protistol. 30, 253-269.

Reize, I. B. \& Melkonian, M., 1989. A new way to investigate living flagellated/ciliated cells in agarose. - Botanica Acta 102, 145-151.

Schnepf, E., Drebes, G. \& Elbrächter, M., 1990. Pirsonia guinardiae, gen. et spec. nov.: A parasitic flagellate on the marine diatom Guinardia flaccida with an unusual mode of food uptake. Helgoländer Meeresunters. 44, 275-293.

Thomsen, H. A., Buck, K. R, Bolt, P. A. \& Garrison, D. I., 1990. Fine structure and biology of Cryothecomonas gen. nov. (Protista incerta sedis) from ice biota. - Can. J. Zool. 69, 1048-1070. 